\title{
Interview
}

\section{Digital asset management makes the grade at Barnes \& Noble College Booksellers - An interview with Mike Hardiman and Tammy Godin of DAM Solutions}

\author{
Mike Hardiman \\ is Director of Sales for The FeedRoom's Digital Asset Management Solutions Group. For the past 15 years, he has held leadership \\ positions with companies such as Eastman Kodak, Engage and Mediabridge that provide digital asset management (DAM) and \\ other technology solutions to global marketing organizations. During the past few years alone, he has witnessed the dramatic \\ evolution of both the technology and business drivers for DAM, and enjoys working with large organizations to understand the \\ end-to-end processes involved in connecting technology and workflow to achieve greater efficiency and process improvement. \\ On a daily basis, he collaborates with leading print vendors, agencies, corporate marketing groups and consulting firms to identify \\ their goals and challenges as they aim to rapidly and effectively implement DAM solutions.
}

\section{Tammy Godin \\ is a senior solutions/project manager working with FeedRoom clients to implement and enhance their use of DAM solutions. As Project Manager, Tammy coordinates customizations for high-profile customers whose needs go beyond a basic DAM solution. Serving clientele across every industry and vertical market has strengthened her understanding of the most efficient ways to organize and retrieve assets. Before joining The FeedRoom, Tammy held IT positions with several academic institutions in the Boston area. Working with the various departments, she continuously sought new ways to keep valuable assets in a single, retrievable place, and quickly realized the business value of DAM. In her current role, she has managed projects for leading organizations, including Mohawk industries, National Geographic, Autodesk, Barnes \& Noble and Bristol-Myers Squibb}

ABSTRACT Headquartered in Basking Ridge, NJ, Barnes \& Noble College Booksellers operates campus bookstores for public and private 4-year colleges and schools. Today, they have more than $\mathbf{7 0 0}$ bookstores at top academic institutions such as Harvard, Yale, University of Pennsylvania and Georgia Tech. In early 2009, they sought a better way to organize and make accessible their digital media assets to local partners online. After an evaluation of digital asset management solutions, they selected ActiveMedia from The FeedRoom. With clear goals, Barnes \& Noble was implemented within only 6 weeks. The following interview with the ActiveMedia project managers provides a glimpse into that process.

Journal of Digital Asset Management (2009) 5, 383-393. doi:10.1057/dam.2009.22

Keywords: DAM; digital asset management; marketing asset management; enterprise media; FeedRoom; ClearStory Systems

Correspondence: Mike Hardiman The FeedRoom, Inc., 205 Hudson Street, New York, NY 10013, USA

E-mail: info@feedroom.com
MM: We're here today with the folks from The FeedRoom. Please introduce yourselves! MH: My name is Mike Hardiman. I'm Director of Sales for the Digital Asset Management Solutions Group at The FeedRoom, a 10-year old company focused on enterprise digital media management. I've been on staff here for nearly 3 years, and have worked in the digital asset management (DAM) market for more than 10 years, with other companies before this. TG: I'm Tammy Godin, senior DAM solutions consultant and project manager for The FeedRoom, responsible for client implementations. I've been with The FeedRoom for almost 5 years, and work together with our customers to ensure that their business requirements are 
being met through the application of FeedRoom technology and solutions.

MM: Why don't you give us a little bit of background on The FeedRoom, and the DAM products - which were added to The FeedRoom product portfolio last year after the acquisition of ClearStory Systems.

MH: The FeedRoom today is the result of two different companies. The FeedRoom on its own - if you want to look at it that way - is an early provider of online video solutions in a SaaS model. They provide enterprise video platforms to manage the whole process of getting videos uploaded, managed and delivered, as well as providing functionality that allows users to interact and analyze on the action that occurs with these Web videos.

ClearStory was acquired by The FeedRoom in December 2008. The company had been around since 1989, but only involved in DAM since 1994 when the company bought WebWare, one of the early DAM pioneers. Since then, ClearStory had taken the WebWare product and done quite a bit of work on the architecture to bring it to where it is today.

It's built on open standards. It's offered both in a SaaS environment, as well as a traditional licensed-software model. The most recent release of the DAM solution includes an embedded workflow engine that allows our customers to quickly configure workflows and automate some of the processes involved with managing a digital media supply chain.

The goal of the combined entities is to move closer to an end-to-end, concept-to-distribution process, as it relates to managing and delivering all types of rich media. When you talk to any organization, there are multiple touchpoints for digital media within every business process both internal and external. The FeedRoom technology and the former ClearStory technology were put together to address this. MM: This sounds like a great place to provide a little bit of a background on your customer, Barnes \& Noble. Most of us know Barnes \& Noble as one of the large bookseller chains. We see them all around North America. Give us your background in terms of Barnes \& Noble as a business, their cultural norms and core operations.

MH: Barnes \& Noble College Booksellers is a privately held sister company of Barnes \&
Noble. Their organization operates campus bookstores for leading universities, colleges and other types of schools. They work closely with each institution to promote their own unique vision, and help them to build a bookstore that adds value to the campus.

MM: What are some of the inherent organizational flows of that particular division?

MH: Well, there are several different groups involved. As this opportunity came to bear, they were looking to augment their current processes across a range of functional areas. In fact, they came to us seeking two separate solutions. They were looking for what they were describing as a traditional DAM repository. And, they were also separately evaluating an RFP or documentmanagement system to help automate and bring consistency to their proposal development process.

The idea behind this is that proposals utilize existing digital assets within the organization. In the beginning, they were looking at those two solutions as separate entities, and hoping they could be integrated.

They saw our ActiveMedia solution and realized that they could combine the best of both worlds. We could manage digital files, documents and the associated rich media in a single system. And even better, provide some workflow behind it to augment and improve their internal processes for managing and creating the marketing and advertising assets they needed to support their individual bookstores, while also enabling the sales team to generate proposals in a more timely fashion. MM: So, as regards Barnes \& Noble College Booksellers, to whom are their sales force delivering proposals?

MH: Their clients are private 4-year colleges, public colleges and 2-year schools. They also deal with several leading law and medical schools.

MM: So these proposals are multimedia PowerPoint decks? What's entailed in a typical proposal? What are some of the elements that go into it?

MH: I'd say that the bulk of the proposals are generally made up of Word documents. But they certainly can include PowerPoint decks. There are images and photos and - not in those particular formats - but sometimes even video that's used to present to new campuses and 
current campuses that they are actively looking to keep.

They often use this marketing material in the body of their proposals and to ensure contracts are up-to-date. To make sure they're using the latest logos and latest sales and marketing - to better support their sales team.

MM: So part of the elements of those proposals would be things like floor plans and point of purchase features?

MH: Absolutely. Anything that you can imagine that would be in a proposal for new business or to keep current business - existed somewhere in the organization. There was some disconnect in ensuring that they had the latest and greatest tools. That's why their plans were moving them in the direction of organizing content in a DAM solution.

MM: Let's start by revisiting the evolution of the customer requirements that you are ultimately satisfied with an enterprise media services platform.

MH: A consultant hired by Barnes \& Noble approached us, but not for this particular project alone. She was tasked with going to the various groups within Barnes \& Noble College Booksellers to try to understand where the business challenges lay. At a very general level, the first communications we received from them detailed functions that would be required for the one or two systems they were seeking.

Essentially, they were looking for a system that could easily catalogue and provide search functionality, and the ability to provide multiple users access from multiple locations. They also wanted varying levels of security and accessibility depending on a user's role. And, they were looking for some automation behind the process such automated e-mails to notify users when new content was available. That was certainly applicable as they updated their corporate proposal structure.

I believe that their time period for internal proposal review was over 3 months. Proposals get updated to reflect the latest branding for Barnes \& Noble College Booksellers. They wanted the ability to notify field teams when new versions of these proposals were available, and to route them electronically, as opposed to sending them snail mail. They wanted the ability to involve multiple people in this collaboration process.
Version control and the ability to involve many people within a centralized solution were all tied to our workflow tool.

They also wanted the ability to easily find and access all their digital media. All the images and all of the photos and ads and other rich media they'd need to be part of the finished proposals.

MM: This all came as a function of the first wave of requirements?

MH: Right. This was really the first point of communication that we had from them, detailing those requirements.

MM: Let me ask you this - how often in large organizations - end-use organizations such as Barnes \& Noble College Booksellers - do you run into an independent consultant that's working on their side of the firewall, in terms of organizing user and customer requirements? MH: Not that often.

MM: Would you say about 10 or 15 per cent? MH: Right.

MM: Generally, have you found that consultants such as the one who worked with Barnes \& Noble to be helpful?

MH: In this case, certainly. I've had experience in the past where - for whatever reason - it hasn't been the case. I don't think there's a fast and true answer to that. It depends on the consultant's motivation. But in this case, it was really a top reason this was a success for both sides.

MM: As you begin to look through these requirements put together by this independent consultant, what was the next phase of the customer requirements' definition and ultimate engagement?

MH: It was a fairly normal sales process in terms of outlining requirements and verifying that we had the ability to meet them. I think in this case, we were able to meet almost 100 per cent of them. There might have been one or two minor details that we didn't necessarily hit right away.

We basically came back to them and said, 'Okay. You've outlined these requirements. Here's how we can respond to that. Do you agree that we've shown and proven to you that we can fulfill these requirements, based on what you've told us?' The answer was 'Yes!'

Then we got a little bit more granular. That was really the next step in the process. They provided specific use-case and specific business- 
case scenarios that we were able to build into a number of demos as Proof-of-Concept (POC) type demos. This gave them confidence we had a solution that could truly support what they were looking for.

MM: Haven't you found it generally true that most end-users, as they begin to think through how best to use DAM and related media services, that they have to see it modeled - on paper or as an online demo. That ultimately results in a fair number of iterative cycles to refine.

MH: I absolutely agree. At The FeedRoom, because we offer our product in a SaaS model, we have the ability to offer what we call 'sandboxes'. Sandboxes don't necessarily have the metadata structure that a final installed customer would have, but the ability to put someone in a sandbox - and certainly to put together some sort of structure that they're comfortable with, at least for testing purposes is absolutely key to any sales process.

MM: The term 'sandbox' means that it's a protected area. It has its own rights and permissions associated with it. It has all of the security protocols with it, correct?

It gives the end-user opportunities to basically kick the tires in a real-life situation.

MH: Yes. That's exactly what it is.

Typically, the sandbox is provided to a small, defined group. Before we provide access to a sandbox, we make sure we understand what the end goal is going to be. History tells us that sometimes when you provide a sandbox without any of that information in place, the client goes back and gets busy doing what they're hired and paid to do every day at their company.

Certainly, we try to control those environments as much as possible. We try to support and promote usage of the technology while they have the opportunity to. But the way you describe it is exactly how we set it up.

Some people require more complex sandboxes than others. An ActiveMedia sandbox is very simple to set up, with a simple metadata structure for a couple of different users and roles with varied privileges. It can be delivered to a client in 24-48 hours.

MM: Then as the Barnes \& Noble folks play in their sandbox, what happened next?

MH: The final piece of the puzzle was where they brought all the key executives into a room and gave us a very particular workflow structure to try to mimic.

That demo was actually very cool. We were literally bouncing a project from person-to-person in the room. Everyone was live. Everyone had a user account. Everyone was logged in. We literally took a project from beginning to end.

One cool part of the demo was the fact that most people were rubber-stamping their task in the workflow. They were approving it and letting it move on to the next person. Except one person tried to get cute and rejected the task. So it would go back to the previous step in the workflow.

That worked like a charm, and it was really something that hit home for them. They saw first-hand how the workflow could really add some value to the process.

MM: So rather than it being a solo user-experience of 'Wow. This is cool', it was more of a tribal experience. Where everyone said, 'Yes. This will definitely cause the survival of the tribe. This is good for the business'.

Ultimately, this isn't about 'my' productivity, but it's about 'our' productivity.

MH: Yes. I would agree 100 per cent. We had the executive sponsors in the room, and the lead people from each individual group. To see the actual workflow bounce from person-to-person helped them to see the value immediately. They know what they face every day, in terms of workflow and collaboration. It was really the hammer in the whole process for us.

MM: At that point, did you need to show them a lot of ROI data?

MH: In this case, we didn't do ROI specifically. We didn't come up with a spreadsheet. It certainly may have been done internally - not to my knowledge. But from The FeedRoom point of view, we did not deliver a formal ROI document.

MM: Generally, I've found in other interviews and first-hand experience, there's a general rule. A thriller application or a thriller demo inversely correlates to the need for hard-data ROI. The more excited leadership is with the demo, the less proof you need to provide to get the funding.

MH: Certainly in this case, those words bore true. I just think it was evident. They set up quite a complicated workflow for us that 
Tammy actually put together and it was just what they were looking for.

MM: Tammy - perhaps you can take us through some of the structure and elements of this workflow that you set up?

TG: Basically, there are a few different groups that needed to be part of this workflow. What you usually ask first is 'What do you want to happen in the end?' Then we put the steps together to get there.

They wanted their proposals approved. They wanted to go through a particular workflow and all different groups of people before that proposal is set public.

MM: Would you say that the review-and-approval process constitutes one of the most inefficient manual, offline workflows?

Therefore, with a media services platform you can deliver some of the most meaningful, significant paybacks by just automating the review-and-approval process?

TG: Absolutely. There's no more going office-to-office with a piece of paper. It's all done automatically. You're notified. If you don't continue your edit or approval, it gets sent to the project manager. That lets him know that you haven't done your job, yet.

You're held accountable for getting your approvals done. There are also edits that happened within their workflow. So the first part of the process was to send these off to the subject-matter experts, and have them decide what actual text should be going into these documents.

They review it and add their text. Perhaps they'll put in some images, as well. Images that took them hours to probably find prior to having a DAM system. That proposal would then move on for approval.

One of the regional managers would then approve that subject matter. Once that was approved, it might get sent to an agency.

MM: With respect to what exactly is getting routed around here - are we talking about a Word document or a PDF?

TG: In this case, it's a Word document with images in it. That's what the proposals are. MM: When I see this in my inbox, I see an image there related to this document. So basically, when I download it and open it up, I'm in Word and I use the 'track changes' function within Word as way of managing the annotation process?

TG: Correct. Then you could re-upload that into the DAM as a new version. So the most recent version is now what's being passed around in this project.

MM: You then link the placed images in the Word document, to the image in the repository. So it all stays linked. Is that correct?

TG: Absolutely. That can be done with compound documents. That's something that happens in the deployment process. I spoke to a few people who were planning to implement compound documents for their proposals in the future. So that happened in phase one of their deployment.

MM: So in terms of setting up workflows, there are a couple of philosophies of automating workflows. One of them is to have a checkbox. As things move through the process, people check off their things. Right?

Those tend to be structured, linear and pretty deterministic. Right?

TG: Correct.

MM: Then you have these other workflows that are more iterative and nonlinear. Especially in this collaborative creation process. How do you really automate or support the faster communication, interaction and collaboration among the people in that creative flow?

TG: With our workflow, we can launch projects within projects. We can have a project going and say, 'Okay. When this project is complete, let's start this next creative project'.

It could be brought to a different group of people. Yes.

MM: That's then taking advantage of some of the underlying business process management capability of your workflow engine. Is that right? TG: Yes. Correct.

MM: At this point, workflow systems begin to distinguish whether you can then have a policy-managed workflow that's more dynamic so you can create open and closed projects within projects, thus making them agile to the events as they're happening in the real world or not.

Can you take us through some of the other underlying abilities to make these policy-managed workflows dynamic and adjustable?

TG: With workflow you can actually have it so that only certain people can manage certain 
projects through the assignment of privileges. If the VP is the only person that's supposed to oversee a project through a process, then the $\mathrm{VP}$ is the only person that's notified during this project. Or, if a project is only to be used, as in the case of Barnes \& Noble, by the group that handles proposals.

MH: Some of the most common uses of workflows that have been deployed so far are some of the simplest things, which are typically manual processes in organizations. I'll give you a few examples.

We get asked by everyone if our DAM solution has the ability to track expired assets. We have the ability to literally monitor through metadata - the expiration dates on assets. It's not a full-fledged rights-management system, but we have the ability - again, through metadata - to manage expiration dates. Users can launch workflows and notifications, and separately remove permissions to download those assets. If the criteria for those assets are actually met meaning their rights have expired - they are automatically made unavailable for download.

One of the other most common workflows we run into is people submitting new assets into the system. We have the ability to siphon where these new assets go. We can launch workflows that task content librarians to approve whether or not all of these assets are going to not only exist in the system, but separately, to get them tagged appropriately before they're actually made public.

There are lots of different little use cases - not just routing and approval.

MM: You bring up another point that I wanted to have you and Tammy speak to. That is the definition and the evolution of the metadata associated with managing this digital media value chain.

TG: Basically, the first step is to get the team together. The amazing thing I find with every implementation is that the initial teams I meet with haven't even seen their new tool. Most of them have been told this is what they're going to be using. We sit down and show them, 'This is what DAM can do'.

To get to the guts of, 'Well, how do we use this tool?' As you know, the key is metadata and taxonomy. Without that, they'll never find the images or the proposals that they're looking for.
So we go through a pretty detailed information-gathering process. Basically, it's 'What type of content are you putting into the system? What are the media types you're putting into the system? What are the users and the roles? What do they need to do within the system?'

Therefore, 'How will they search? What are they looking for? What do they need within a finger-snap of the day?'

We have to talk about the security around that, because metadata can impact security. 'Is it approved yet? Is it for public use or private use at this point in time?'

As Mike stated, we can run workflows based on any criteria. Is it expired? Is it approved? There's quite a tedious process that we go through of gathering all of that information up front.

MM: The tools you use to gather or define requirements for metadata, do you use worksheets or do you whiteboard it? Do you use wire frames?

TG: A little bit of everything. I find different clients learn differently. I always have work sheets that I ask them to read and fill out prior to our first engagement. I also have a call with them and show them visually what I mean by the term 'metadata', because some people are hearing that term for the first time.

I actually think the most exciting part of it is the whiteboard session. Having them get up and start white boarding out what we've been talking about. Taking the sheets that I've had them fill out, and making it happen.

Mike earlier spoke about the sandbox. We take that one step further in the deployment process. Once we've gathered that information and feel we're maybe 90 per cent there, I show them samples. I give them my best feelings for what I think they should do. I then give them what I call a POC site.

It's like 95 per cent where I think it needs to be with their metadata and with their collection structure. That's a folder-like structure that houses the assets. Then the metadata describes them.

They literally go in, hands-on. I upload some of their assets and tag them with the metadata. That's when all the light bulbs go off. That helps us to achieve the last 5 per cent. 
MM: I have this favorite rule. It's the 90/90 rule. In any significant project where there's some change-management entailed, the first 90 per cent of the project entails just all that you said. You gather it all up and put it together in a functional prototype.

At that point, the second 90 per cent shows up. So after your 90 per cent of the work, you have 90 per cent left.

That second 90 per cent are all of the soft elements of the system design. It's the training the support - the negotiation - the explanation the reframing.

As well as accommodating some very specific needs and criteria, in terms of the way it should look and the underlying metadata structure.

TG: Actually, I use this approach a lot. I'll say to them in a nice tone or jokingly when some individual will say, 'Well, I describe it this way ...' I'll say to them, 'Well, it's not all about you. It's about the group. Let's come up with a common term that makes sense to everybody'. MM: Yes.

TG: That's a challenge, sometimes to find that term that everybody agrees upon, that will be the best search term.

As far as security goes - in the case of Barnes \& Noble - some of those proposals and contracts are very private and confidential. We needed to determine when we set up their system and their folders and their hierarchy what folders could be seen by whom.

So, another aspect of the business analysis was 'Who are the people using it? What roles do they have? Also, what permissions do they have? What can they do once they access the DAM system?'

So there's another whole level we had to discuss and work through. Having the POC sites to be able to show them how security works was key to helping them understand. MM: POC being the sandbox?

TG: Correct, it is part of the deployment process. So when we go through training, users can understand privileges and permissions.

MM: What are some of the tricks that you use to speed things along?

TG: Personally, I do all of the training, as well. So, having the knowledge of that POC site I give them my suggestions on ways that they should use the system, now that they have their assets organized.
One of the things that I noticed with Barnes \& Noble, specifically, was that they needed to get their new assets into the system quickly. They wanted to make sure that they were approved, but there were four or five different groups that needed to have these assets in different locations.

During the training session, I knew that this was something they wanted to accomplish.

So I set up 'hot' folders for all of the five different groups - a location where people could drop their assets. Each asset then dynamically populates ActiveMedia with its associated metadata.

So understanding each customer's use case and putting together what I think would solve their problem during training - helped me. Because some of the training was, 'How do you want to set up your drop boxes? How do you want to set up your hot folders?' So - having set up specific examples helped me to speed up that process of training and doing the actual full deployment for them.

MM: I've seen situations where you have hot folders within hot folders within hot folders. A user drags it from the top-level folder into one of two or three subordinate folders, and then into another two or three subordinate folders.

Each time they move it from one folder to the next, a new set of metadata gets appended to the asset.

So it was kind of a visual drag-and-drop meta-tagging process that a creative person can accomplish. Because it's already in their 'aesthetic idiom', of dragging things around in space, and having things happen.

Does your DAM system support nesting folders within hot folders?

TG: Yes. You can have a hot folder within a hot folder.

MM: Perfect. That's actually one of the best practices that we've begun to document. Speed metatagging through drag-and-drop nested hot folders.

TG: The other use case that I came up with for Barnes \& Noble during that final phase of the project included the ability of their agencies and photographers to upload new assets, as well, without logging into ActiveMedia. Having these hot folders gives them a place to just drop it in, and they don't have to $\log$ in. 
MM: So this hot folder sits on an agency-created desktop or traffic or production coordinator's desktop? All they do is just drag it onto that desktop and it just kind of magically - through $\mathrm{ftp}$ - uploads into an ingest queue?

TG: Correct.

MM: With respect to Barnes \& Noble, were there any other tips and tricks that either you developed at Barnes \& Noble or that they really validated?

TG: I think that the consultant was probably most instrumental. Her biggest obstacle was 'Who is going to be the lead person on this project?' Once she goes away and once I go away, who's going to take ownership?

MM: Right.

TG: That was something that was difficult I think for both of us. It's a fairly new deployment. I still see e-mails every day. We help them through some of their questions and whatnot. But I think the hard part was determining who was going to take ownership of that. I don't know if that could have been determined better in the beginning of the process.

MM: We've found in that context that when introducing the notion of DAM, as an operational capability of an end-use organization, is that the accountabilities piece is the part that is often most overlooked or underdeveloped in terms of the overall operational capability of a DAM services within an organization.

Particularly, you've identified it already. Once we kind of fire up the system and people are going to use it, who is the person that has overall corporate accountability for the care and feeding of this system?

TG: Yes. Absolutely.

MM: One of the things that we've found is, it's really important that on the client's side, there be the equivalent of a database administrator, but basically a DAM services director - or a supervisor - who has that overall corporate charter of content governance, and is ultimately the one point of coordination and orchestration for how to evolve the system within that particular company.

TG: Yes.

I will say, during training we had 20 of end-users in the room. That's a large number for training on a DAM system. She and
I conversed prior to and agreed we needed to figure out who was going to take some ownership.

So we targeted those people that really 'got it', and made a big deal of the fact that they got it. We said, 'Okay. You understand the metadata. You understand the structure. What group are you in?' We tried to engage them to want to take more ownership on the project.

MM: Usually that's a requirement for leadership within the organization. To designate someone as 'You are my go-to person. You are the responsible, accountable party for making sure that this operational capability continues to deliver the efficiencies that we paid for'.

TG: Right. Absolutely.

MM: As a consultant, you can only do so much. Right? But at the end of the day, it's basically part of someone's daily operational accountability.

TG: Yes.

MM: So, at this point, Barnes \& Noble has not yet come up to speed with respect to a designated chief DAM services person.

TG: They're on their way. Now that they've been doing a lot of uploading and using the system, I think there are a couple of people who are stepping up to the plate. It's evolving. They have a marketing department. Then there's also the sales team. And the corporate team.

MH: We've talked a lot about the proposal process. That's all done through corporate marketing, the group responsible for selling to colleges that are not already working with Barnes \& Noble.

Store operations are something that we haven't really touched upon during the course of this interview. But store operations constitute the people that put together programs and materials for the 700 client bookstores that they currently operate. This includes any marketing or promotions that are provided - as well as internal training. Video is also used for training purposes, internally. So all of those assets are going to be in the system, as well.

These people that we're talking about - the people that have stepped up and taken some leadership - represent people from both of these different groups.

MM: You say you've got 700 or so retail footprints out there? They are doing local area 
marketing and promotions, downloading assets and/or promotional material.

Now, in the store operation itself - in one of those actual 700 operations - do they actually modify creative assets for their needs? Or does the creative come from a central group?

MH: I think it's a combination of the two. There are certainly going to be instances where these people are going to be able to make a simple address change to some sort of flyer or brochure to support some kind of marketing program that's happening. But I think also, the finished product.

We talked a little bit earlier about this system kind of managing the up-front process. But I guess this would be a small part of the end process - the distribution process. To make content created centrally by the store operations group readily available to floor personnel.

MM: Are you using any kind of dedicated document servers or document publishing capabilities attached to the DAM?

MH: That wasn't part of our engagement. The part was just to get the content organized and to help provide some workflow functionality. MM: What sort of reports and analytics have you begun to see the system produce? Either in terms of workflow, cycle time, cost-efficiencies any sorts of meaningful reports developed from the activity journals?

MH: I would say it's still a work in progress. They're still building the system out with the content being sourced from all over the organization. That's yet to be determined. But I know that they're keenly interested in understanding who's logging into the system and who's accessing what assets.

We fully expect to deliver that sort of information at some point in the near future. MM: In terms of a dashboard that they might look at, what are some of the database benchmarks that you'd anticipate, that a Barnes \& Noble would want?

MH: They really haven't. That really wasn't part of their original requirements, but we can certainly provide them - not through a dashboard, necessarily, but through just a small professional services engagement. This would give them the ability to see who logged in, what new assets were created and who downloaded them.
These are things that we've done pretty consistently with most of our other clients. But that request hasn't yet come from the client. MM: Can you speak to any of the early returns, in terms of efficiency gains or cost-savings? TG: I would say right now at this point they have five VPs, and I think 45 regional directors that support those VPs. Those administrative assistants all had their own offices and databases. Prior to the DAM, their images were all over the place. Now those five administrators are finding their images more quickly for their VPs.

They're no longer saying, 'Do you have it in your database? Maybe it's in the New York office. Does the New Jersey office have it?' Now, it's centrally seen online.

They're putting all of their most recent assets up, and they're notifying people. So the administrative assistants are getting notified, 'These 100 new assets have just been uploaded to the DAM'.

MM: That's a good point.

About how many users and assets are we talking about online or soon-to-be-online? TG: I'm not sure of the exact number they plan on putting online. But currently they have close to about 3000 assets. I believe they plan on serving as many as 700 users.

MH: We went in with workflow. We went in with the concept of getting their content organized. But certainly, as we advise all of our clients, the first important step in a successful implementation is to build that taxonomy. Build the metadata structure. Get your content in. Then we start to figure out where we can enhance their productivity through workflow and other tools in the system.

MM: That really dovetails nicely with a theme of DAM as not necessarily a solution or a system, but really as a business strategy. It's a strategy by which to continually optimize or learn how to optimize your resources, so as to achieve greater and greater competitive advantage.

DAM as a strategy tends to evolve in an organic way. It leverages or exploits the cultural norms and opportunities of that particular organization. Driven by leadership, and implemented from the bottom-up.

MH: Exactly.

MM: This really then calls attention to the importance of not just staying engaged with the 
customer, but to staying engaged with an evolving requirements discovery process.

MH: I would agree. Even in the 10 years I've been in this market, certainly from the sales side of it, we always want to put our best foot forward, and show them all the fancy buttons and the bells and whistles. But invariably, it comes down to the first step in the process hasn't changed. The first step in the process is 'How do I want to manage this content? Let's get going that way. How do I want to build my metadata structure?'

Then we can start to figure out whether it's buttons or services or processes. Then we can start to identify even more ways to take advantage of the system that's been put in place.

MM: Right. Aside from the organizational changes and the evolution of how that organization gets things done, at the end of the day, we're really talking about the evolution of the metadata and taxonomy that really constitutes the guts of a DAM system.

MH: Absolutely. I think it's a key part of it.

We try to get as much of it right as we can from the get-go. But it's always going to be an evolving process.

But I don't think people ever really get to a final metadata structure or taxonomy. There are always new businesses and new product lines. There are always new types of media, and new ways that people want to describe their content.

But the quicker we can get our arms around the view of the business, and how they want to model that through a DAM, the faster we can get onto, 'Okay. Let's look at other opportunities in terms of revenue generation, target marketing and things like that'.

MM: Looking forward now, 2 years out, what sort of developments do you anticipate Barnes \& Noble exploiting?

TG: I think the first thing that we're going to do in the near future is to have more workflow training.

MM: Right.

TG: I'm actually going to spend some time with them. I usually recommend once you've used the system for 3-6 months, that you go out and do a more advanced training for the users. I think from that, we can expand the deployment for greater traction and better results.
What I do foresee is video content becoming a bigger part of this, part of the conversations going forward, especially around the management of the Barnes \& Noble training videos.

MM: Right.

MH: There are two areas of expansion. First, is that we initially deployed 100 users, but there is the potential within this account to bring on more than 700 users, representing other groups within the organization.

We have already received a call from one other group that's curious as to what's happening in store operations and corporate marketing. So we're just starting to engage in conversations there.

Second, their use of online video. They've told us that it's going to expand dramatically over the next 12-18 months. They're very interested in understanding FeedRoom's offerings for enterprise online video delivery. MM: One last thing - what points of convergence do you envision with the DAM and the FeedRoom online video ecosystem, taking into account the core content operations and content management of Barnes \& Noble?

MH: Well, all of that is media, right? So all of that needs to be managed in a centralized repository, eventually. That's the goal.

It would be even better, of course, from our standpoint, if they're using both applications. The DAM to manage all of that content - and the online video technology to deliver that content via their Websites.

MM: Do you know what CMS platform they use for their primary Web properties?

MH: I think it's homegrown at Barnes \& Noble College Booksellers, right now. If you go online to Barnes \& Noble College Booksellers, there is very limited video on their site currently. It's been identified as a major opportunity there.

We're certainly trying to educate them as to where we're moving to as a company, to better support those types of business goals.

MM: This sounds like a great place to start wrapping up. Mike - Tammy - any kind of last comments with respect to the story of Barnes \& Noble College Booksellers and their use of DAM?

MH: What's unique about this case is that there was a separate process around creating 
their proposals. Originally the goal was to actually have two systems and somehow integrate them. But with workflow added on top of the actual DAM technology piece, we were able to answer both needs in a single system.

The deployment itself happened in less than 6 weeks. A lot of that time was spent on the back and forth of the business analysis. So from the kick-off meeting to the go-live, it was very quick. That was another big thing they wanted, to move forward quickly. They definitely wanted to strike while the iron was hot. MM: Well, that sounds like a great place to conclude, Mike and Tammy. Thank you so much. 